\title{
Helping veterans achieve work: A Veterans Health Administration nationwide survey examining effective job development practices in the community
}

Marina Kukla, Alan B. McGuire, Amy M. Strasburger, Elizabeth Belanger, Shana K. Bakken

RUNNING HEAD: Job Development Practices

\section{Acknowledgements}

This study was supported by Veterans Health Administration Rehabilitation Research and Development grant 1IK2RX0009

\begin{abstract}
Objective: Veterans Health Administration vocational services assist veterans with mental illness to acquire jobs; one major component of these services is job development. The purpose of this study was to characterize the nature of effective job development practices and to examine perceptions and intensity of job development services. Methods: A national mixed-methods online survey of 233 Veterans Health Administration vocational providers collected data regarding frequency of employer contacts, perceptions of job development ease/difficulty, and effective job development practices when dealing with employers. Qualitative responses elucidating effective practices were analyzed using content analysis. Results: Vocational providers had a modest number of job development employer contacts across two weeks ( $\mathrm{M}=$ 11.0, $\mathrm{SD}=10.6)$ and fewer were face-to-face $(\mathrm{M}=7.6, \mathrm{SD}=8.4)$. Over $70 \%$ of participants perceived job development to be difficult. Six major themes emerged regarding effective job development practices with employers: using an employer focused approach; utilizing a targeted marketing strategy; engaging in preparation and follow-up; going about the employer interaction
\end{abstract}


with genuineness, resilience, and a strong interpersonal orientation; serving as an advocate for veterans and educator of employers; utilizing specific employer tailored strategies such as arranging a one-on-one meeting with a decision maker and touring the business, individualizing a pre-scripted sales pitch, connecting on a personal level, and engaging in ongoing communication to solidify the working relationship. Conclusions and implications for practice: Respondents highlight several potentially effective job development strategies; tools and resources may be developed around these strategies to bolster job development implementation and allow opportunities for fruitful employer interactions.

Keywords: job development; supported employment; mental illness; veterans; work 
Introduction

Unemployment is a major problem for veterans with mental illness (Zivin et al., 2011). In response, the Veterans Health Administration (VA) has implemented effective vocational programs such as supported employment (SE). Job development, the multi-faceted process of assisting veterans to attain jobs, is a critical component of SE (Glover \& Frounfelker, 2011), and has been associated with better employment outcomes (Bolton, Bellini, \& Brookings, 2000; Larson et al., 2011; Leff et al., 2005). Job development components have not been well defined and vary across research groups; however, some general elements do have empirical support. First, job development generally involves forming relationships with veterans seeking work (Donnell, Lustig, \& Strauser, 2004), characterized by a client-specific approach in which the vocational worker seeks to match the client with jobs fitting their needs and preferences. Effective job matching is associated with longer job tenure amongst persons with mental illness (Huff, Rapp, \& Campbell, 2008; Kukla \& Bond, 2012). Secondly, job development involves building networking relationships with employers (Whitley, Kostick, \& Bush, 2010), and third, using these connections to create specific job opportunities or pursue open positions in collaboration with veterans and employers (e.g., Nietupski \& Hamre-Nietupski, 2000).

Despite its importance, job development is a difficult element to implement (Swanson et al., 2011). For instance, frontline SE providers in the community report that job development is troublesome and often not worth the effort (Cook, Razzano, Straiton, \& Ross, 1994). Similarly, a large study found that SE staff were fearful of providing job development services and did not possess adequate skills to effectively perform job development (Drake, Merrens, \& Lynde, 2005). Furthermore, vocational providers in the community report that job development is especially challenging, involving a series of failures. Prospective studies of job development 
have found that clients with mental illness received one job offer per seven interviews and the overwhelming majority of employer contacts on the part of job developers did not result in a job interview or job offer (Gervey \& Kowal, 1995). Other studies have found that an even greater number of employer contacts are required to secure job placements in SE (Cook et al., 1994). In addition, factors specific to veterans present further challenges to effective job development. For instance, veterans may have difficulty translating military skills into the civilian workplace (e.g., Stern, 2017), experience physical and cognitive barriers that manifest on the job (Kukla, Bonfils, \& Salyers, 2015; Kukla, McGuire, \& Salyers, 2016a), and may face veteran-related stereotypes and stigma on the part of employers (Kukla et al., 2016a; Rudstam, Strobel Gower, \& Cook, 2012).

A major contributing factor to difficult job development implementation is the lack of an empirically based framework regarding what constitutes effective job development practice. Accordingly, vocational providers have emphasized the complexity of job development (Kukla, McGuire, \& Salyers, 2016b) and the need for additional guidance with regard to effective job development strategies. Another potential issue is lack of generalizability of recommended job development practices; previous studies examining job development have utilized small samples that may not generalize to other settings with differing resources and populations (e.g., Migliore, Butterworth, Nord, Cox, \& Gelb, 2012).

To address the shortcomings in previous studies and build understanding of job development practice, this study sought to accomplish three goals. First, this study qualitatively described effective job development practices in interactions with employers. The focus on interactions with employers stems from growing support for the importance of building employer relationships to bolster work outcomes (Drake, Bond, \& Becker, 2012). Further, perspectives of 
a large nationally representative sample of VA vocational providers were utilized because of their expertise in providing job development services and regular frontline work with employers, veterans, and other stakeholders; these valuable experiences will provide a wide range of views and insights to more fully capture effective job development strategies in routine practice. Second, in order to further portray the nature of job development, this study characterized providers’ perceptions of job development ease and difficulty. Third, the frequency of job development contacts with community employers was delineated as a preliminary step towards creating a normative standard for the field.

\section{Methods}

Sampling

Participants included 233 VA staff persons from across the United States who provide community-base job development services. The sample was comprised of frontline staff $(\mathrm{N}=180)$ and supervisors/managers ( $\mathrm{N}=53)$ stemming from VA supported employment $(\mathrm{N}=135)$, housing assistance $(\mathrm{N}=68)$, and community-based transitional work programs $(\mathrm{N}=30)$. These VA programs provide job development services and collaborate with employers towards the common goal of assisting veterans to find and keep jobs that fit their needs, preferences, and personal objectives toward recovery.

Procedure

In collaboration with the VA Office of Therapeutic and Supported Employment Services, an electronic link to the online job development survey was distributed via email to all VA vocational providers. The online survey probed job development practices using open ended questions, asked participants to rate job development ease/difficulty, and indicate the frequency of total job development contacts with employers and contacts occurring face-to-face. Following 
the provision of informed consent, participants provided background information and completed the survey. Data were collected between June and July 2015. All procedures were approved by the Institutional Review Boards at the university and VAMC.

Measures

Devised for this study as primary data collection, the survey consisted of questions regarding the 1) Frequency of job development contacts with employers within the past two weeks and 2) job development contacts occurring in the community (i.e. "face to face” contacts), within the past two weeks. 3) Perceptions of job development were assessed by one item measured on a 1 to 10 Likert scale: "Overall, how easy/difficult is it to effectively job develop for the Veterans whom you serve?” The scale went from 1-“easiest” to 10-“most difficult.” 4) Strategies used during successful job development employer interactions were explored using an open-ended survey question: "Think about a recent time when you met with an employer and it went well. What job development strategies helped you get to a successful outcome?” Analyses

Using SPSS 20, descriptive statistics were generated to characterize the intensity of job development employer contacts across two weeks, face-to-face contacts with employers across two weeks, and perceptions of job development ease/difficulty.

Open ended questions pertaining to effective job development practices with employers were analyzed using a conventional content analysis (Hsieh \& Shannon, 2005) aided by matrix analysis to bolster rapid synthesis and summarization of findings (Averill, 2002). Three coders read the responses and identified themes using an inductive approach (Crabtree \& Miller, 1999). Coders then met and discussed emerging themes in the data and resolved discrepancies. During the ongoing coding process, the coders wrote memos, resulting in continued revision of codes 
and a final set of focused codes. Focused coding was then used to code the remainder of responses. As displayed in Table 1, frequency of codes was based on number of responses, rather than number of participants; for instance, one participant could have more than one response per theme (e.g., a participant could provide a response containing two aspects pertinent to using a employer focused approach in job development).

\section{Results}

Frequency of job development employer contacts and face-to-face contacts

Respondents reported a mean of 10.6 employer contacts across two weeks ( $\mathrm{N}=210$, $\mathrm{M}=11.0 ; \mathrm{SD}=10.6$ across two weeks) including face-to-face, phone, and email contact. As shown in Figure 1, one-third of participants reported a range of 5 or fewer employer contacts across two weeks. In comparison, participants reported a mean of 7.6 contacts occurring face-to-face with employers across two weeks ( $N=210, M=7.6, S D=8.4)$. As shown in Figure 2, nearly $60 \%$ of staff reported 5 or fewer face-to-face employer contacts during this period; $15 \%$ of participants reported no face-to-face job development contacts with employers during the past two weeks. Perceptions of Job Development

Respondents generally perceived job development as difficult ( $N=105 ; \mathrm{M}=6.3, \mathrm{SD}=2.0)$. Over 70\% (N=74) of respondents considered job development difficult (difficulty score greater than 5) and over 30\% ( $\mathrm{N=32)}$ view job development as very difficult (difficulty score 8 or higher).

Effective Job Development Strategies with Employers

As displayed in Table 1, themes describing effective job development strategies with employers fell under 11 codes; we review the six most frequently occurring themes. 
The most effective strategy was utilizing an employer focused stance heavily emphasizing employer needs, including hiring and personnel needs, business-specific needs, and assessment of the fit between the employer’s needs and the veteran’s skills. Respondents also emphasized the utility of a "dual customer” approach in which the vocational provider balances the needs and preferences of both the veteran and the employer. Further, respondents noted the importance of being respectful of the employer's time and priorities by discussing the employer’s needs first, prior to initiating a conversation about veteran needs.

Second, employing a marketing strategy was stressed as a highly effective job development approach. Components of a useful marketing approach include highlighting the benefits of hiring veterans with disabilities consistent with the moral imperative of "hire a hero". In addition, effective strategies include presenting a dual customer, balanced cost/benefit analysis of hiring veterans with particular emphasis on the tax incentives involved. Utilization of formal marketing materials and strategies were also viewed as useful.

Third, vocational providers reported undertaking targeted preparation and follow-up for the employer interaction to ensure positive outcomes. Sub-themes in this domain include proper preparation for the meeting, such as seeking information and background materials on the business, making a one-on-one appointment with a decision-maker, and planning a visit at a convenient time for the employer. In addition, proper follow-up after the employer interaction included timely contact, via phone, email, and face-to-face communication.

Fourth, vocational provider characteristics perceived as key to successful employer interactions included genuineness, persistence, resilience, and a strong interpersonal orientation. Genuineness included honesty about the vocational program and the strengths and limitations of hiring veterans. Persistence referred to ongoing efforts to "sell” the veteran and complete the job 
acquisition process, “not giving up” in response to job development barriers, and diligence in following up on job applications and interviews. Resilience referred to the need for vocational providers to rebound in response to the many failures involved in employer interactions, such as failure to secure a job offer. Furthermore, vocational providers must be interpersonally oriented and possess strong networking skills based on clear communication and attentive listening to the employers’ needs.

Fifth, vocational providers reported successful employer interactions when they embrace the dual roles of advocate for veterans and educator of employers. This dual role serves multiple functions, such as educating employers about disability and veteran culture, dispelling stigma, job carving, or working with employers to form a job opportunity based on the needs, preferences, and strengths of the veteran, and assisting with the arrangement of appropriate workplace accommodations for veterans.

Sixth, a set of specific recommended practices with employers emerged as important to job development success. These targeted practices tended to converge with other themes, including vocational worker characteristics and behaviors such as persistence, ample preparation and follow-up for employer interactions, and networking strategies. Effective practices include preparation of employer and vocational program specific marketing materials, pre-scripting the “sales pitch,” arranging a meeting with a hiring manager, requesting a tour of the business facility, visiting the employer during "slow” business hours, personally patronizing the business, and sending "thank you” notes after the meeting. Second, follow-up and "checking in” with employers should be recurrent to solidify and further the networking relationship. Third, a helpful approach within the context of networking and collaboration with employers includes 
connecting on a personal level, by recognizing shared interests, hobbies, and/or experiences, as well as acknowledging those of the employer in an appropriate manner.

\section{Discussion}

Utilizing a national sample of VA vocational providers, this study examined perspectives on a challenging, yet critical component of job development services-interactions with employers. Findings highlight several strategies that were viewed as promotive of positive employment outcomes. These elements are in line with past studies of job development for nonveterans (Swanson, Becker, \& Bond, 2013) and are consistent with components of quality job development in the Individual Placement and Support (IPS) supported employment fidelity scale (Becker, Swanson, Bond, \& Merrens, 2011); this is important given that overall fidelity to the IPS model has been associated with stronger competitive employment outcomes (Bond, Drake, \& Becker, 2008). Of note, the most frequently emphasized element was maintaining an employer focus by targeting the needs and interests of the business. Relatedly, utilizing a prepared and balanced veteran-specific marketing strategy also incorporating societal norms of hiring veterans and external incentives oftentimes lead to further substantive conversations about hiring. Respondents also remarked on how to go about approaching interactions, including genuineness about the vocational program and veterans, as well as persistence and resilience in the face of many employment barriers. Relatedly, several specific recommended job development practices centered upon preparedness and targeted strategies to ensure individual and more meaningful employer interactions, forming personal connections with employers, and engaging in ongoing communication to bolster the professional relationship. In addition, in agreement with previous research regarding job development for non-veterans, employing a genuine interpersonal stance 
to bolster relationship building and utilizing a dual customer approach giving attention to both the needs of the veteran and employer were highlighted (Glover \& Frounfelker, 2013).

Moreover, in comparison to IPS fidelity standards (Becker et al., 2011), the majority of vocational providers reported engaging in a relatively modest number of job development contacts overall and fewer face-to-face interactions with employers in the community. Though not all survey respondents provided IPS and other individual vocational rehabilitation models were represented, this is noteworthy, as overall intensity of services and relationship with employers, which occurs most successfully through interaction, have been found to predict more favorable employment outcomes, including more job acquisitions and longer job tenure (Corbière, Brouwers, Lanctôt, \& van Weeghel, 2013; McGuire, Bond, Clendenning, \& Kukla, 2011). Likewise, vocational providers who spend more time in the community also have higher client employment rates and 90-day employment rates (Taylor \& Bond, 2014).

Adding to the extant literature (Cook et al., 1994), most respondents considered job development to be difficult and implementation challenging. It is possible that the difficulty of job development contributed to fewer job development contacts with employers. For example, it may be that providers found job development tasks daunting or experienced mixed or lack of success in these tasks, leading to fewer future attempts to develop jobs with employers. Furthermore, these findings considered together with the qualitative themes demonstrating the multifaceted nature of job development suggest the need for supports and tools to improve job development implementation. Specifically, leadership supportive of job development activities may incorporate flexible scheduling practices to accommodate employer availability, sufficient allotment of time in the community for job development, and access to necessary job development resources, such as phones, laptops, and vehicles. Moreover, policies regarding 
vocational provider productivity requirements that may be incompatible with or hinder engagement in community job development (e.g., requirements to spend the majority of hours doing face-to-face work with veterans in the office) should be re-evaluated and adjusted accordingly. Future research should focus on the development and testing of tailored job development resources, including a tool to track job development workload and employer contacts, as well as training tools, such as a job development training manual incorporating effective in vivo strategies, such as veteran-centered job carving and employer tailored marketing approaches.

The study has limitations that warrant mention. The primary limitation is the subjective nature of the data. Specifically, it is unknown which job development strategies predict positive job development outcomes, and the relationship between frequency of contacts with employers and work outcomes, such as job acquisition and long-term work success is unclear. Future research should seek to examine these key quantitative relationships using VA work outcomes data to further delineate effective practices and determine the optimal frequency of job development contact with employers. In addition, participants’ years of experience conducting job development is unknown; it is possible this variable impacted their perceptions, nature, and frequency of job development practice. Further work should also seek to understand the influence of these key factors.

\section{Conclusions}

This nationwide survey of VA vocational providers underscored the complex and difficult nature of job development services. Several effective strategies in interactions with employers were found. Future research should seek to link these strategies with veteran work 
outcomes and identify helpful job development implementation approaches within the VA services context. 
Table 1: Themes describing effective job development strategies with employers

\begin{tabular}{|c|c|c|c|}
\hline Frequency & Code Name & Code Description & Examples \\
\hline 43 & Employer focus & $\begin{array}{l}\text { Approach that centers on the needs and } \\
\text { interests of the employer }\end{array}$ & $\begin{array}{l}\text { Focusing job development efforts on the employer's business and } \\
\text { personnel needs; dual customer approach; determining how employers } \\
\text { operate; showing interest in the business }\end{array}$ \\
\hline 42 & Marketing Strategy & $\begin{array}{l}\text { Centerpiece of employer interaction is } \\
\text { marketing or selling of veterans and/or the } \\
\text { vocational program }\end{array}$ & $\begin{array}{l}\text { Discussing the many benefits of hiring veterans; cost/benefit business } \\
\text { analysis; emphasis on proper job match in consideration of employer } \\
\text { needs; utilization of customized marketing materials; selling veteran } \\
\text { skills and expertise }\end{array}$ \\
\hline 42 & $\begin{array}{l}\text { Interaction preparation } \\
\text { and follow up }\end{array}$ & $\begin{array}{l}\text { Activities involved in preparing to meet } \\
\text { with an employer and timely and effective } \\
\text { follow up with employers after the } \\
\text { interaction }\end{array}$ & $\begin{array}{l}\text { Researching information on the business; preparing business cards \& } \\
\text { flyers; preparing a marketing pitch; making a meeting agenda; making } \\
\text { an appointment vs. cold call; pre-scripting; getting information on the } \\
\text { application process directly from employer; timely and thorough } \\
\text { follow up }\end{array}$ \\
\hline 33 & $\begin{array}{l}\text { Vocational provider } \\
\text { characteristics }\end{array}$ & $\begin{array}{l}\text { Successful vocational provider } \\
\text { characteristics to develop employer } \\
\text { relationships }\end{array}$ & $\begin{array}{l}\text { Honesty/ sincerity with regard to veteran strengths and weaknesses as } \\
\text { workers, persistence in approach, good communication \& listening, } \\
\text { persuasiveness, passionate, proactive, fearless, flexible, solution } \\
\text { focused }\end{array}$ \\
\hline 28 & Advocating/educating & $\begin{array}{l}\text { Vocational provider educates the employer } \\
\text { and advocates on behalf of veterans }\end{array}$ & $\begin{array}{l}\text { Educating the employer regarding best strategies to work with veterans } \\
\text { and accommodate disabilities; educating employers on mental } \\
\text { illness/homelessness \& dispelling stigma; education on CWT/SE } \\
\text { program and services; addressing veteran barriers with the employer; } \\
\text { disclosure decisions }\end{array}$ \\
\hline 27 & $\begin{array}{l}\text { Recommended } \\
\text { practices with } \\
\text { employers }\end{array}$ & $\begin{array}{l}\text { What to do/not to do in an employer } \\
\text { interaction }\end{array}$ & $\begin{array}{l}\text { Frequent employer contact after the initial meeting; visiting employer } \\
\text { at a convenient time; finding the best contact at a business; forming a } \\
\text { personal relationship with employer prior to moving on to business } \\
\text { relationship; meet one on one; patronize the business; actively } \\
\text { following up on veteran applications; making an appointment vs. cold } \\
\text { visit; using multiple simultaneous strategies }\end{array}$ \\
\hline 20 & $\begin{array}{l}\text { Developing } \\
\text { individualized Veteran } \\
\text { centered jobs }\end{array}$ & $\begin{array}{l}\text { Interaction individualized based on veteran } \\
\text { background, preferences, and needs }\end{array}$ & $\begin{array}{l}\text { Job development based on the preferences, needs, strengths, and } \\
\text { barriers of the veteran. Veteran specific jobs and needs assessment. } \\
\text { Job carving. Also includes development of veterans specific } \\
\text { transitional work sites }\end{array}$ \\
\hline 10 & $\begin{array}{l}\text { Relationships with } \\
\text { employers }\end{array}$ & $\begin{array}{l}\text { Emphasis on relationship building, } \\
\text { partnerships, rapport building with } \\
\text { employers toward the goal of developing } \\
\text { jobs }\end{array}$ & $\begin{array}{l}\text { Developing jobs based on current employer relationships; following } \\
\text { up with employers with the purpose of building and maintaining long- } \\
\text { term relationships; building relationships prior to pursuing veteran } \\
\text { employment opportunities at that business }\end{array}$ \\
\hline
\end{tabular}




\begin{tabular}{clll}
\hline Frequency & Code Name & Code Description & Examples \\
\hline 5 & Veteran Involvement & $\begin{array}{l}\text { Active involvement of veterans in } \\
\text { employer interactions }\end{array}$ & $\begin{array}{l}\text { Bringing veterans to meet employers early on in the relationship } \\
\text { building process. Also includes comments regarding the } \\
\text { inappropriateness of involving veterans in job development activities } \\
\text { "Veteran friendly" businesses; employers not interested in making } \\
\text { accommodations; employer stigma and stereotypes; employers in a } \\
\text { certain sector that impact their desire to work with veterans, e.g., big } \\
\text { box companies; } \\
\text { Meeting as a team and problem solving vocational barriers that may } \\
\text { impact employer interactions; team-based employer networking; } \\
\text { supervisor guidance in interaction approach }\end{array}$ \\
\hline
\end{tabular}


Figure 1: Frequency of Employer Contacts Across Two Weeks, N=210

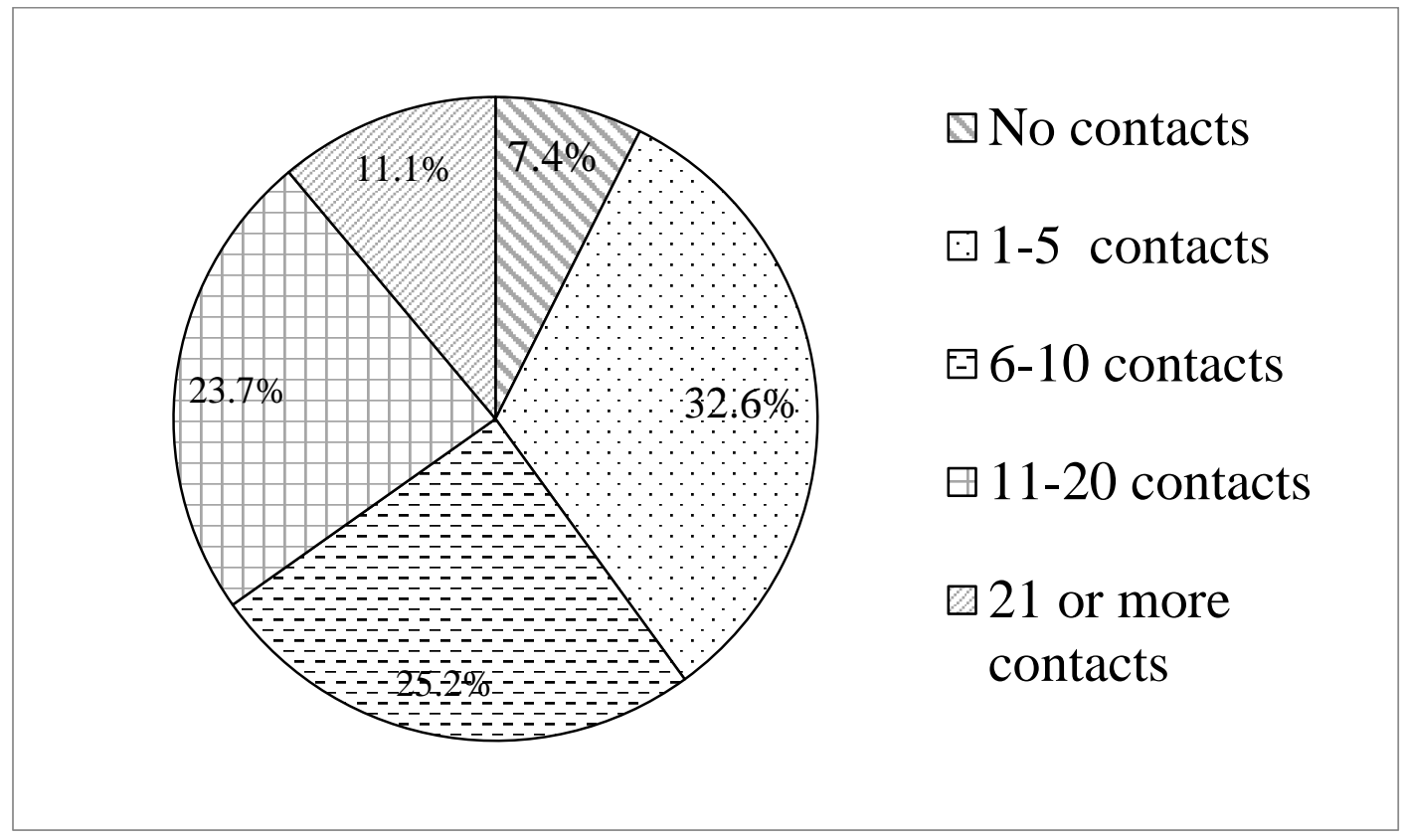

Figure 2: Face to Face Employer Contacts Across 2 Weeks, N=210

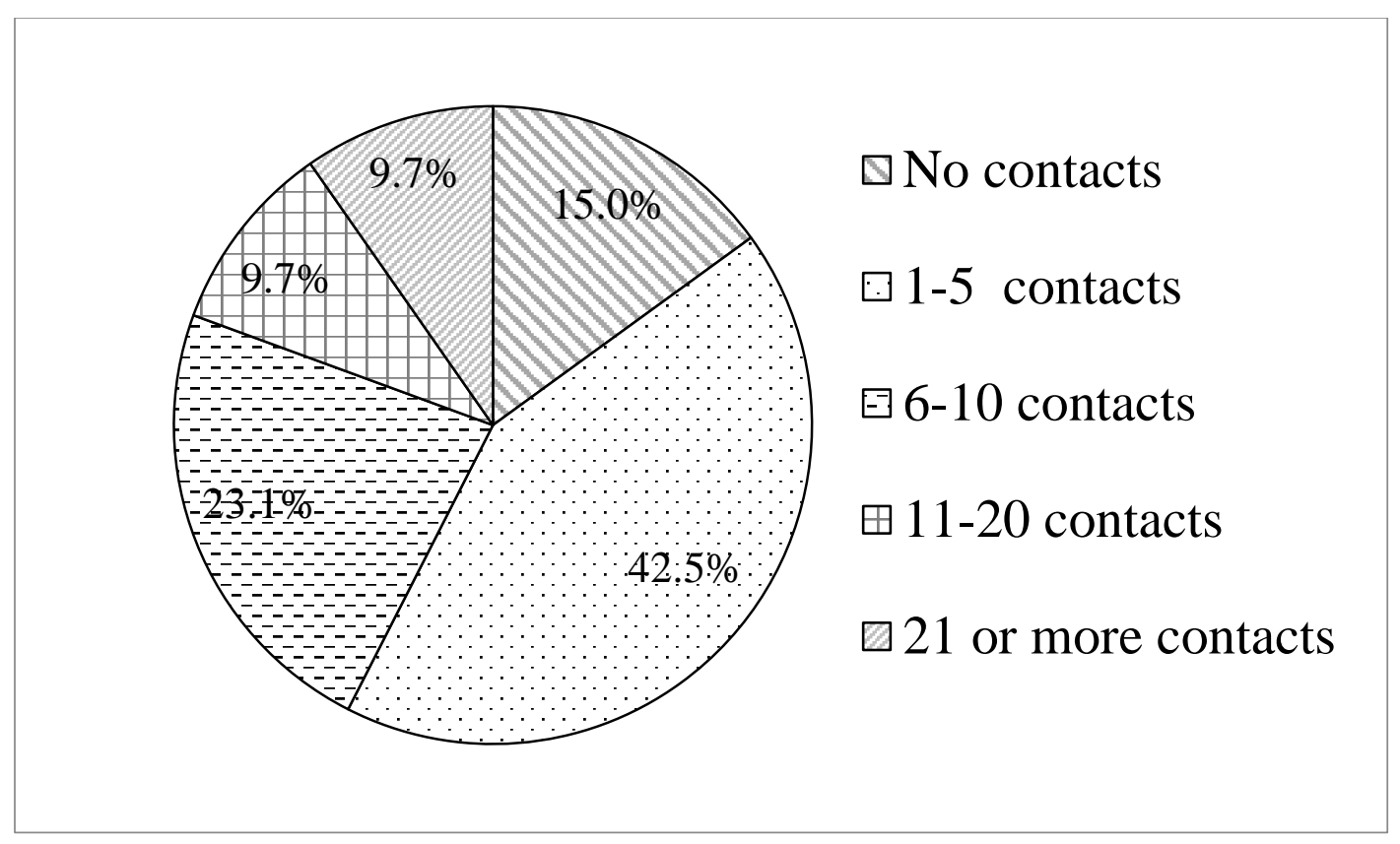




\section{References}

Averill, J. B. (2002). Matrix analysis as a complementary analytic strategy in qualitative inquiry. Qualitative health research, 12(6), 855-866.

Becker, D. R., Swanson, S., Bond, G. R., \& Merrens, M. R. (2011). Evidence-based Supported Employment Fidelity Review Manual (2nd ed. ed.).

Bolton, B. F., Bellini, J. L., \& Brookings, J. B. (2000). Predicting client employment outcomes from personal history, functional limitations, and rehabilitation services. Rehabilitation Counseling Bulletin, 44(1), 10-21.

Bond, G. R., Drake, R. E., \& Becker, D. R. (2008). An update on randomized controlled trials of evidence-based supported employment. Psychiatric Rehabilitation Journal, 31(4), 280.

Cook, J. A., Razzano, L. A., Straiton, D., \& Ross, Y. (1994). Cultivation and maintenance of relationships with employers of people with psychiatric disabilities. Psychosocial Rehabilitation Journal, 17(3), 103.

Corbière, M., Brouwers, E., Lanctôt, N., \& van Weeghel, J. (2013). Employment Specialist Competencies for Supported Employment Programs. Journal of Occupational Rehabilitation, 1-14.

Crabtree, B. F., \& Miller, W. L. (1999). Doing qualitative research (2nd ed. Vol. 3). Thousand Oaks, CA: Sage.

Donnell, C. M., Lustig, D. C., \& Strauser, D. R. (2004). The Working Alliance: Rehabilitation Outcomes for Persons with Severe Mental Illness. Journal of Rehabilitation, 70(2).

Drake, R. E., Bond, G. R., \& Becker, D. R. (2012). IPS supported employment: An evidencebased approach to supported employment. New York, NY: Oxford University Press. 
Drake, R. E., Merrens, M. R., \& Lynde, D. W. (2005). Evidence-based mental health practice: A textbook: WW Norton.

Gervey, R., \& Kowal, H. (1995). Job development strategies for placing persons with psychiatric disabilities into supported employment jobs in a large city. Psychiatric Rehabilitation Journal, 18(4), 95-113.

Glover, C. M., \& Frounfelker, R. L. (2011). Competencies of employment specialists for effective job development. American Journal of Psychiatric Rehabilitation, 14(3), 198211.

Glover, C. M., \& Frounfelker, R. L. (2013). Competencies of more and less successful employment specialists. Community mental health journal, 49(3), 311-316.

Hsieh, H.-F., \& Shannon, S. E. (2005). Three approaches to qualitative content analysis. Qualitative health research, 15(9), 1277-1288.

Huff, S. W., Rapp, C. A., \& Campbell, S. R. (2008). "Every day is not always jell-o": a qualitative study of factors affecting job tenure. Psychiatr Rehabil J, 31(3), 211-218. doi:6UGV7776312T6412 [pii]

10.2975/31.3.2008.211.218

Kukla, M., \& Bond, G. R. (2012). Job Match and Job Tenure in Persons with Severe Mental Illness. Journal of Rehabilitation, 78(1).

Kukla, M., Bonfils, K. A., \& Salyers, M. P. (2015). Factors impacting work success in Veterans with mental health disorders: A Veteran-focused mixed methods pilot study. Journal of Vocational Rehabilitation, 43(1), 51-66. 
Kukla, M., McGuire, A. B., \& Salyers, M. P. (2016a). Barriers and Facilitators Related to Work Success for Veterans in Supported Employment: A Nationwide Provider Survey. Psychiatric Services, 67, 412-417. doi:DOI:10.1176/appi.ps.201500108

Kukla, M., McGuire, A. B., \& Salyers, M. P. (2016b). Rural and urban supported employment programs in the Veterans Health Administration: Comparison of barriers and facilitators to vocational achievement for veterans experiencing mental illnesses. Psychiatric Rehabilitation Journal, 39(2), 129.

Larson, J. E., Ryan, C. B., Wassel, A. K., Kaszynski, K. L., Ibara, L., Glenn, T. L., \& Boyle, M. G. (2011). Analyses of employment incentives and barriers for individuals with psychiatric disabilities. Rehabilitation Psychology, 56(2), 145.

Leff, H. S., Cook, J. A., Gold, P. B., Toprac, M., Blyler, C., Goldberg, R. W., . . CamachoGonsalves, T. (2005). Effects of job development and job support on competitive employment of persons with severe mental illness. Psychiatric Services, 56(10), 12371244.

McGuire, A. B., Bond, G. R., Clendenning, D. R., \& Kukla, M. (2011). Service intensity as a predictor of competitive employment in an individual placement and support model. Psychiatric Services, 62(9), 1066-1072.

Migliore, A., Butterworth, J., Nord, D., Cox, M., \& Gelb, A. (2012). Implementation of job development practices. Intellectual and developmental disabilities, 50(3), 207-218.

Nietupski, J. A., \& Hamre-Nietupski, S. (2000). A systematic process for carving supported employment positions for people with severe disabilities. Journal of Developmental and Physical Disabilities, 12(2), 103-119. 
Rudstam, H., Strobel Gower, W., \& Cook, L. (2012). Beyond yellow ribbons: Are employers prepared to hire, accommodate and retain returning veterans with disabilities? Journal of Vocational Rehabilitation, 36(2), 87-95.

Stern, L. (2017). Post 9/11 Veterans With Service-Connected Disabilities and their Transition to the Civilian Workforce: A Review of the Literature. Advances in Developing Human Resources, 19(1), 66-77.

Swanson, S., Becker, D. R., \& Bond, G. R. (2013). Job development guidelines in supported employment. Psychiatric Rehabilitation Journal, 36(2), 122.

Swanson, S., Burson, K., Harper, J., Johnson, B., Litvak, J., McDowell, M., \& Weinstein, G. (2011). Implementation issues for IPS supported employment: Stakeholders share their strategies. American Journal of Psychiatric Rehabilitation, 14(3), 165-180.

Taylor, A. C., \& Bond, G. R. (2014). Employment Specialist Competencies as Predictors of Employment Outcomes. Community mental health journal, 50(1), 31-40.

Whitley, R., Kostick, K. M., \& Bush, P. W. (2010). Desirable characteristics and competencies of supported employment specialists: An empirically-grounded framework. Administration and Policy in Mental Health and Mental Health Services Research, 37(6), 509-519.

Zivin, K., Bohnert, A. S., Mezuk, B., Ilgen, M. A., Welsh, D., Ratliff, S., ... Kilbourne, A. M. (2011). Employment status of patients in the VA health system: implications for mental health services. Psychiatric Services, 62(1), 35-38. 